\title{
Responsibility for Psychological Sense of Community and Well-Being in Old Age: A Qualitative Study of Urban Older Adults in Norway
}

\author{
Nina Kavita Heggen Bahl1 ${ }^{*}$, Hilde Eileen Nafstad², Rolv Mikkel Blakar², Amy Østertun Geirdal ${ }^{3}$ \\ ${ }^{1}$ Department of Psychology, Norwegian University of Science and Technology, Trondheim, Norway \\ ${ }^{2}$ Department of Psychology, University of Oslo, Oslo, Norway \\ ${ }^{3}$ Department of Social Work, Child Welfare and Social Policy, Oslo and Akershus University College of Applied Sciences, Oslo, Norway \\ Email: *nina.bahl@ntnu.no
}

How to cite this paper: Bahl, N.K.H., Nafstad, H.E., Blakar, R.M. and Geirdal, A.Ø. (2017) Responsibility for Psychological Sense of Community and Well-Being in Old Age: A Qualitative Study of Urban Older Adults in Norway. Open Journal of Social Sciences, 5, 321-338.

https://doi.org/10.4236/jss.2017.57020

Received: April 18, 2017

Accepted: July 18, 2017

Published: July 21, 2017

Copyright (c) 2017 by authors and Scientific Research Publishing Inc. This work is licensed under the Creative Commons Attribution International License (CC BY 4.0).

http://creativecommons.org/licenses/by/4.0/

\begin{abstract}
The purpose of the present study is to explore older adults' understanding and conceptualizations of the concept "psychological sense of community" (PSOC) as experiences of belonging and being part of seem to be important in old age. Twelve older informants from Oslo (the capital of Norway) were interviewed. A thematic and discourse analytical approach was used to identify and depict the most central themes in the older adults' meaning of PSOC in-depth and in relation to context. The findings show that there are important parts of Norwegian older adults' meanings of PSOC that goes beyond dimensions included in the predominant conceptualization of PSOC. "Individual responsibility for PSOC in old age", identified as the most salient theme, reflects core Norwegian cultural values and provides new insight to premises of PSOC and well-being in old age. Furthermore, the findings in this Scandinavian sample extend the understanding of older adults' efforts to maintain their PSOC and well-being through life-changing transitions.
\end{abstract}

\section{Keywords}

Well-Being, Psychological Sense of Community, Old Age, Culture, Social Responsibility, Norway

\section{Introduction}

The aging of Western populations emphasizes the need for more research on the well-being of older people. How older adults are socially connected is a highly relevant research issue for future studies of older adults' well-being, as relations, 
to be part of, to belong, and to feel committed to seem to be important aspects of individual well-being [1]-[6]. Using the concept "psychological sense of community" (PSOC), community psychology has approached peoples' experiences of belonging and to be part of [7] [8] [9] [10] [11]. Most used today is McMillan and Chavis' conceptualization of PSOC as consisting of four dimensions: a) membership, or a feeling of belonging and identification with the community; b) influence, or the sense of acceptable community influence and, at the same time, feeling some control and influence over the community; c) integration and fulfilment of needs, or the reinforcement that members receive by having their needs met through their community's resources and their contribution to it; and d) shared emotional connection, or the sense that members in the community have shared, and will continue to share, a history of negative and positive events, places and experiences together. These dimensions have also been shown to be central in older adults' conceptualizations and understanding of PSOC [12]. This paper presents an analysis of urban older adults meaning of PSOC useful to community psychology as well as current PSOC research [13] [14]. Our findings carry implications for development and applications of services and interventions from public elder care.

Taking as our position that PSOC is a context-sensitive concept embedded in culture [9] [15]-[20] experienced differently among various age groups [12] [21] [22] [23] and that cultural context affects our meanings and experiences of aging and thereby our well-being [24], we are interested in how urban older adults in Norway, one of the Scandinavian welfare states, explain and define PSOC.

\section{The Norwegian Context and Older Adults}

Norway as a culture has traditionally been characterized by communal values, social equality, equal distribution of wealth [25], a strong "work ethic" [26] [27] and the "Law of Jante", all elements that encourage individuals to show humbleness, or not putting oneself above the community and others [29]. Triandis and Gelfand [30] categorised the Norwegian culture as a culture of "horizontal individualism" characterised by a shared understanding of one's self more or less as every other self, or as "egalitarian individualism" as Gullestad (1991) described it. Triandis and Gelfand [30] as well as Gullestad [26] thus describe the Norwegian culture as individualistic but not a culture that favors hierarchy or competitiveness, as vertical individualistic cultures often do [31]. However, Norwegian values have recently changed towards a stronger vertical individualism [32].

Most older people in Norway are living at home by themselves or with a partner. The last two generations of older adults have, given that they are in good health, been rather self-reliant [33]. In Norway, retirement pension is provided universally to all individuals independent of earlier employment, and the state is perceived as the main economic provider for older adults [34]. However, al-

${ }^{1}$ The Law of Jante is composed of 10 "commandments", e.g. "Thou shalt not fancy thyself better than us" [28] Sandemose, A. (1933) En flyktning krysser sitt spor: fortelling om en morders barndom. Gyldendal, Oslo. It is a frequently recurring theme in the public discourse when public figures express an attitude of uniqueness or putting oneself above the community in some way. 
though most older adults are not economically dependent upon their family, there is a great deal of solidarity between the generations within the typical Norwegian family; almost $50 \%$ of adults visit their older parents weekly, and older adults often live in the same area or close to their grown children. Norwegian older adults under 80 years old are often active, not only when it comes to social participation with friends and neighbors, but also within their local community [33]. This high level of social activity concurs with the findings of a new study demonstrating that Norway has the lowest prevalence of loneliness among older adults, compared to West, East and South European countries [35].

The typical big-city context of Norway differs from the more rural Norway where social cohesion values tend to be higher [36]. Using a qualitative approach, we interviewed older people in Oslo about how they understand and define PSOC.

\section{Method}

\subsection{Informants}

Twelve older adults (six women and six men) participated. Nine of them were asked by the head of different senior centers if they would like to participate. The rest of the informants (three) were recruited by the researcher (the first author) either through these centers or acquaintances.

As there are marked health differences between older adults east and west of Oslo-people to the west of Oslo have better health [37] —an equal number of informants (six) from the east and west of Oslo were decided to be included.

Older populations in Western societies are increasingly diverse. People from Pakistan represent the immigrant group, which is the largest and has the longest history of residency (many came in the 1970s) in Oslo [38] [39] and two older adults (one male, one female) born in Pakistan were also included in the sample. One had resided in Oslo in 21 years, the other 28 years. These informants did not stand out as different from other informants with respect to the findings.

The following demographic variables characterized the sample (Table 1).

Thus the sample reflects central demographic variations of the old age population in Oslo.

\subsection{Instruments}

In earlier studies, interviews were used for getting in-depth information about PSOC as this method gives the informants the opportunity to express in their own words what PSOC is for them [17] [18] [23] [40] [41]. However, to ensure that the informants had the chance to express themselves and at the same time have some overall structure to the interview, a semi-structured interview was chosen [42]. The interview guide consisted of two sections; part one included questions about demographic variables (age, gender, marital status, highest level of education, residential area of Oslo, years of residence in area of Oslo, number

of children and number of family members residing in their home), and if they 
Table 1. Demographical characteristics of the sample.

\begin{tabular}{|c|c|c|c|c|c|c|}
\hline Informant $^{2}$ & $\begin{array}{c}\text { Marital } \\
\text { status }\end{array}$ & Highest level of education & $\begin{array}{l}\text { Residential } \\
\text { area of } \\
\text { Oslo }\end{array}$ & $\begin{array}{c}\text { Years of } \\
\text { residency } \\
\text { in area of } \\
\text { Oslo }\end{array}$ & $\begin{array}{c}\text { Number } \\
\text { of } \\
\text { children }\end{array}$ & $\begin{array}{l}\text { Number of } \\
\text { family } \\
\text { members } \\
\text { in the home }\end{array}$ \\
\hline F851 & Widow & MA & West & 80 & 3 & 0 \\
\hline F852 & Widow & High school & West & 25 & 3 & 0 \\
\hline F853 & Divorced & Primary school & West & 5 & 2 & 0 \\
\hline F854 & Widow & High school & West & 25 & 4 & 0 \\
\hline F71 & Divorced & Non-degree granting college & East & 16 & 2 & 0 \\
\hline F62 & Married & MA & East & 21 & 2 & 1 \\
\hline M78 & Divorced & BA & West & 30 & 1 & 0 \\
\hline M80 & Married & MA & West & 9 & 2 & 1 \\
\hline M85 & Widower & Non-degree granting college & East & 5 & 0 & 0 \\
\hline M75 & Widower & High school & East & 47 & 2 & 0 \\
\hline M75 & Widower & Non-degree granting college & East & 3 & 4 & 0 \\
\hline M69 & Married & MA & East & 28 & 4 & 5 \\
\hline
\end{tabular}

had influence in any social or political group). Part two dealt with open-ended questions concerning meaning of community and PSOC (e.g. "What comes to your mind when you think of the word "community"?", "Is there any particular community you are referring to when you think of this?", "What meaning do you relate to the concept "sense of community"?" and "In which way would you say a sense of community is important to you as an elderly person?"). Follow up questions about PSOC and well-being were asked (e.g. "What would you say that to experience a "well-being" means to you?" "Would you say that a sense of community is important for your well-being?").

The interviews were recorded by a digital voice recorder, and varied from 27 minutes to 1 hour and 26 minutes. National ethical guidelines of research were applied for and accepted by the Norwegian Centre for Research Data.

\subsection{Analyses}

Thematic analysis. Thematic or theme focused approaches are a methodology often used for analyzing data from interviews. Braun and Clarke (2006) provide a systematic and rigorous thematic approach to identify and analyze frequent and central themes in the meaning systems of informants [43] [44] [45], and was used as the first initial analysis of the data set. The thematic analysis was based on verbatim transcriptions of the second open section of the semi-structured interview. Moreover, it was decided to combine the thematic analysis with discourse analysis to meet our aim of exploring the meaning of PSOC in-depth and

${ }^{2}$ Informants are represented with codes indicating gender ( $F$, female and $M$, male) and the informant's age. As four of female informants were 85 years old, they have been given an additional number $(1-4)$ to separate them from each other. 
in a context-sensitive way.

The first four steps of the thematic analysis were used to capture the most frequently mentioned and common themes [44] [45]. The researcher first read through the data set to become familiar with the material, then coded the data set by hand to generate initial codes, and thereafter, went back to the data set and searched for codes that could have been missed in the first read-through. Codes were then organized in themes; repeated and coherent pattern of meaning that is distinctive from other themes. To review the themes, the most central characteristics and sub-elements of each theme were noted. Furthermore, the researcher went through the data set to see if and how each theme interacted with other themes, and if demographic variables played a role in each theme. Finally, the review of the themes was extended by highlighting the data set by different colors for each theme to check to what degree the themes covered the whole data set and if the non-colored parts explained the samples' understanding of PSOC further. In this process, seven themes were identified in the material. They were: "Responsibility and initiative", "Acquaintance", "Decease of community members", "Community member health", "Shared elements", "Respect and tolerance for diversity" and "Care and support".

Discourse analysis. Within discourse analytical approaches it is a priori assumed that the meaning of concepts changes with time. Moreover, change happens through discourse, which can be understood as the interaction between spoken language (how individuals and groups speak about something) and cultural values as part of a meaning system prescribing and describing the common sense of society [46] [47] [48] [49]. There is a variety of concrete techniques or tools of discourse analysis [47] [50]. The approach of Gee [51] for analyzing meaning systems in a data set is relevant for us as he argues that what is taken for granted or common sense is most central for understanding meaning. Gee's "The making strange tool" focuses on the elements taken for granted in the data set; the researcher inquires continually into what the informants implicitly take as natural and true.

When applying "The making strange tool" in the further analysis it became evident that some words used by the older people were recurring in the data set. The following six words were typically used when referring to taken-for-granted notions: "should" (bør), "ought to" (burde), "must” (må), "is indeed” (er jo), "absolutely" (absolutt), “one"/“you” (man), and "of course” (selvfølgelig). It was decided to use these words as search words in a systematic analysis of the whole data set. Searches were also undertaken for "should not" (skal ikke), "is not" (er ikke), "normal" (normal) and "ordinary" (vanlig) but they did not add any more detailed information. From these searches, interview extracts about taken-for-granted elements about PSOC were copied. In the data set, eight reoccurring taken-for-granted aspects of PSOC were identified: "reciprocity", "feedback, response and acceptance", "good manners and amiability", "trust, honesty and loyalty", "good atmosphere", "flexibility", "safety", and "participation”. Reviewing the data through "The making strange tool" confirmed some of the themes 
identified through the thematic analysis, gave a more in-depth understanding of these themes and provided the possibility of revealing additional themes/overlapping themes. The findings from this analysis were evaluated and then merged with the findings from the thematic analysis, making sure that both the most central and common themes as well as the taken-for-granted dimensions of PSOC in the data set were included in the final themes to be presented in the study.

Context is a central concept in discourse analysis [47] [48] [50]. As the present study aimed to understand the meaning of PSOC for older adults in a context-sensitive way, Gee's "Framing problem tool" was also used. According to Gee (2014), this tool can be used to analyse meaning in context by repeatedly asking and analyzing how contextual aspects affect the meaning of peoples' utterances. Any aspect of context can affect the meaning of an utterance and the researcher pushes one's knowledge of the context as far as possible to see if aspects of the context are relevant. This tool was applied in the analysis of the most central theme in the informants' meaning (presented below) by asking how any of the utterances from the informants reflected the described elements of the Norwegian context. This way of thinking provided a more context-sensitive understanding of the chosen findings by connecting the meaning of the informants with the larger cultural meaning systems within their context.

\section{Findings}

The above analyses produced several themes important to the Norwegian older adult samples' meanings and understandings of PSOC. The themes were about making an effort; how they thought other community members felt about them and their membership; what they shared with the others; and PSOC as both geographical and relational. The typical referent communities the informants mentioned were friends, family, neighbourhood, and finally, senior centres, organisations and unions they were members of.

Taken together, the themes could be divided into two categories: premises for PSOC and components of PSOC. Components were themes reflecting typical conceptualisations or descriptions of PSOC (PSOC is ...), while premises were themes reflecting central aspects for the older adults in order to experience PSOC (in order to have a PSOC...).

\subsection{Components of the Older Adults' Meaning of PSOC}

Firstly, "acquaintance" was something particularly important for the older adults" geographical PSOC:

F71: "Yes! [I feel a sense of community] here. I meet a lot of old acquaintances if I go down to Sagene [city area of residence] ... or the centre here".

Activities associated with acquaintances was often "face-to-face"-visiting others, drinking coffee together at local cafés, going to cultural events and just saying "hi" to each other when meeting. 
"Shared elements" was a more general component of PSOC; it could be a shared community goal, shared interests, activities and history with other members. However, most mentioned was "shared understandings" between community members:

M85: "Sense of community is that we have a shared understanding".

Moreover, the older adults described that it was central that other members showed them respect:

F62: "I show up [in the community], so everyone shows me respect ... Respect ... I mean, there [in the community] they think that "she is part of us".

Furthermore, "care and compassion" was mentioned in describing PSOC. As a theme it was about the older adult's definition of a good community and the experience of care and compassion shared between community members:

M80: "Yes, it [a characteristic of a good community] is indeed ... warmth, consideration and caring".

F854: "The fact that we wish each other well [is something I connect to PSOC]".

Like showing care and compassion, most actions and interactions in the communities of the older adults were expected to be of a reciprocal character:

F62: "And I think that if you do something yourself ... you have to contribute ... so that you can receive also. If you don't do something, how can you expect that others will help you?"

A final theme was about "trust, honesty and safety" between community members:

M80: "It [Sense of community] is ... that people are ... not dependent on me, but can count on me".

These components demonstrate that the dimensions as part of McMillan and Chavis' conceptualization of PSOC (membership, influence, integration and fulfilment of needs and a shared emotional connection) are central to the meanings of PSOC among older adults in the Norwegian context. However, there were other themes important in our Norwegian city sample.

\subsection{Premises of the Older Adults' Meaning of PSOC}

Three other themes, in fact reflecting premises important and central for the older Norwegian adults, were identified. The first two mentioned premises were exposed as part of the most salient theme in the data: "Individual responsibility for PSOC in old age" and the sub-theme "Adaptation to transitions". All informants in their discourse of PSOC highlighted responsibility for maintaining PSOC. The third theme was "acceptance" as an important premise for individual PSOC. As M80 formulated this third theme:

"So ... a condition for having ... a sense of community is that ... you are ac- 
cepted".

As the following analyses will demonstrate, the first two premises were underscored as especially important premises for PSOC in old age

\subsection{Individual Responsibility for PSOC in Old Age}

What stood out as most central when our older Norwegian informants described their understanding of PSOC was their own responsibility for PSOC. Taking responsibility for their own PSOC was about taking initiative and participating in community activities. This theme operated as something "taken for granted" and words like "shall" (skal) and "must" (må) were typically used.

F851: "That is what I am saying: you cannot just sit at home; you have to take initiative yourself".

This individual responsibility was referred to as especially important in old age, as being part of a community could no longer be taken for given as in a younger age.

F853: "Yes, that [community participation] is eh ... really ... very important. Not to just sit at home ... and get stuck ... Very important for health and mind ... young people are at work, right? And meet ... have a community at work ... and in their everyday life ... While ... Eh ... old people ... are, if they don't take initiative themselves, then they are just sitting at home ..."

The informants also expressed that this initiative effort concerned and was about the choice to be part of the community or not.

M80: "In every community, or in a society, you have people who won't make an effort ... and they ... they keep themselves outside, by themselves ... And those who don't participate in the community, they are naturally outside (the community)".

Individual responsibility of PSOC was also demonstrated by the informants' understanding that being lonely was seen as being in their own control.

F854: “That is ... you, you create your own old age ... I don't have to feel lonely, I can just take ... if I feel lonely I can make a phone call or I can go across the street to a friend."

"Individual responsibility" (eget ansvar), "initiative" (initiativ), "effort" (innsats) and "to accomplish" (yte) were words typically used by the informants when describing their meaning of PSOC.

The sub-theme "Adaptation to transitions" was about psychosocial transitions in old age such as the loss of a spouse, friends or community members because of death or illness and the decline in their own health:

F853: "No... [I don't have any experience with community members being excluded or leaving the community]. Yes, there are some who are dead ... 
but that's another way of leaving. And ... some have become demented ... . So that's another way of losing as well".

F854: “... I take health into account immediately. Because I won't sit here and say that ... because some are so sick, and have such ailments and pain that ... [The same effort is not required]".

Going through such transitions, the community of older adults reduced the demands and expectations of the individual member's responsibility and initiative of community participation, even though at the same time they all on their own part emphasised their own responsibility.

Decline in health was the most frequently mentioned transition. For example, dementia and severe pain were mentioned as reducing the expectations the community and the older adult adults had towards others. Going through hip surgery, cancer or chronic obstructive pulmonary disease, the older adults still required efforts and initiative in community participation from themselves, however:

F853: "You are solely responsible for ... eh ... both your own health and your own life".

Moreover, to prevent decline in health, community participation and involvement were seen as something depending on one's own individual effort; one has to try to go on:

M78: "Yes, to participate is important in old age and to be involved in order to ... eh ... be included and continue in the community. There is one thing I'm afraid of, and that is to get dementia. And I have found out that I ... have to be involved [to stay healthy]".

As shown, the expectations the older individuals held to themselves were strong; and they were not about how you were feeling, what changes in life have affected you, but how you deal with the changes, how you adapt to them.

To never give up, to be part of community and good health were mentioned as the fundamental premises for the older adult's well-being:

F851: "Yes, I believe so [That sense of community is important for well-being]. That you want to, I think ... if you only sit at home and do nothing ... do not get out and ... contribute ... meet people and things like that ... then you cannot experience well-being".

F854: "Its [well-being] very much ... what should I say ... yes, the more I have to attend to the more well-being I have".

F71: "I can say that ... I have well-being if I get up in the morning and I'm not ... that I am ambulatory".

M80: "It [well-being] is about health as well. That you have a good health".

The relationship between PSOC and well-being was described as going both ways. Well-being could promote community participation: 
F62: "Mhm [Sense of community is important for well-being]. Because I have noticed that if I feel good, I participate more [in the community]".

Finally, in our analysis we found an interaction between "residential area of Oslo" and our theme; older adults to the west of Oslo often reported to invest their efforts in more communities compared to informants residing in the east. We assume that this observation reflects the health discrepancy between older adults in east and west of Oslo [37]. Being ill restricts mobility and thereby the number of communities one can participate in. Moreover, age and gender played a role as more women than men described experiences of loss, and the majority of informants describing experiences of loss were 85 years and above. This makes sense as women live longer than men, and with age they are more likely to experience others' death and own illness. However, importantly, informants, independent of demographic background, stressed the importance of individual responsibility and health as premises for PSOC and well-being.

To sum up, other people, organizations or institutions were not mentioned as responsible or accountable for the informants' PSOC; they rendered themselves totally responsible. Moreover, even though many older people in Norway live near their family and have frequent contact with family members [33], support from the family was not taken for granted when experiencing demanding transitions in old age. In one way or the other, the informants strongly focused on their own efforts to cope and secure their well-being. They required themselves to manage and to adapt to the changing situations of life.

There are several strong cultural meaning systems in the Norwegian society that can help to understand the older adult Norwegian informants' way of conceiving PSOC and well-being primarily as an outcome of personal efforts and individual "responsibility taking". First, the horizontal individualism having pervaded in the Norwegian context for a long time indicates a meaning system of Norwegians as individualist persons. People prefer to decide for themselves what to do and how to do it [30]. Another key aspect in the Norwegian value system is, as also discussed, the strong "work ethic" of Protestantism and early industrial capitalism [26] [27]. These meaning systems demand making great efforts and working hard in order to "deserve" a good life. These values of hard work were also predominant in the Norwegian society when our informants grew up (1930-50) [27] [52]. Our informants' expectations and practices to be self-reliant is in fact a practice that has grown increasingly stronger since 1990 in Norwegian society [33], implying that many of today's older adults had self-reliant parents, uncles and aunts who acted as role models for how older people "should" think and behave. Finally, the recent move away from traditional communal values to more individualistic values and policies in the Norwegian society may also have made individual responsibility, initiative and involvement an important part of the older adult discourse to manage to adapt to the larger context of more neo-liberal and private practices (Nafstad et al., 2007). As a consequence, older Norwegians may have changed from being the "deserving 
citizen" to the "adapting citizen"; a shift that carries far reaching implications for the individual's responsibility for their own PSOC and well-being.

\section{Limitations}

Discourse analyses are based on assumptions of dialectical relation between the context and discourse practice [51]. Knowledge obtained from discourse analysis has, therefore, been questioned in terms of a form of falsification that may result from these assumptions, reading meaning into text rather than out of text (Haig, 2004). This is an important limitation that context-sensitive studies interpreting findings in terms of cultural frames of reference are subjected to. However, the possibility of this form of falsification has to be accepted in order to meet with the aim and value of a context-sensitive understanding. Importantly, in this study thematic analysis was undertaken first. The discourse analysis was thus based on findings sensitive to the informants' meaning of PSOC.

Qualitative analysis of cultural context also calls for the researchers themselves to be scrutinised. The bi-cultural perspective (Norwegian-Indian) of the researcher in the current study is argued to be of importance in this regard. Advantages of this perspective are the researcher's "outside" perspective, which make it easier to point out biases and taken-for-granted notions assumed to be natural, which actually are cultural, but also the "inside" perspective, and which provide a thorough understanding of the Norwegian culture and for the researcher to be perceived as Norwegian by the informants. This perspective, however, is likely to have introduced some biases as well; cultural notions (such as the role of individualism in the main theme), may have been understood as cultural, because it stood out as very different from an Indian culture, while actually being related to the individual aspects of the informants, such as personality or their situation. This limitation is especially central considering the researcher's community and cultural psychological background. The perspective is also likely to have made the researcher blind to taken-for-granted elements, which the researcher shared with the informants.

Older people living in a big city were interviewed. The results may differ from more rural Norway. Given the age range of the sample ( $62-85$ years), the results may not apply to people who are older than the sample (over 85 years). Finally, the assumptions of who would be regarded as suitable informants by senior center leaders as well as acquaintances may have affected the representativeness of the sample. As in any qualitative study, it is possible that informants who were social and talk-active were more likely to be chosen or wanting to participate, despite a clear instruction from the researcher that any informant would be of interest.

\section{Discussion and Concluding Remarks}

As shown, the older Norwegian city informants' meaning system of PSOC reflected several dimensions in the conceptualisation of McMillan and Chavis [10].

"Acquaintance" and "acceptance" are a central part of "membership"; "reciproc- 
ity" in "influence"; "respect and tolerance", "trust, honesty and loyalty" and "care and compassion" in "integration and fulfilment of needs" and "shared elements" in "shared emotional connection".

However, as presented, their own responsibility for PSOC in old age was a very important part of the Norwegian informants' meaning system of PSOC. Given psychosocial transitions such as retirement, children getting their own family, and friends and community members dying, PSOC for older adults is no longer automatically maintained by going to a work place, being part of a family or meeting up with long-lasting friends. Old age, then, in many ways, demands people to make efforts and take responsibility themselves in maintaining their own PSOC and well-being. Responsibility has also been discussed by some scholars in the field of PSOC research [10] [53] [54] [55]. The kind of responsibility the informants in our study were concerned about, however, was different from the social responsibility that has so far been focused upon in PSOC research. Our informants strongly focused on their individual responsibility to secure their PSOC in old age and thereby their well-being.

As presented, this type of responsibility is largely reflected in core Norwegian cultural values: the Protestant "work ethic" [26] [27], horizontal individualism and the more recent vertical individualism [25] [30]. The above findings could thus be considered as expected. However, the Norwegian culture can, as presented, be characterised both as a horizontal individualistic culture and at the same time a welfare state [25] [26] [31] [32]. One could, therefore, expect that in such a culture not only individual efforts, but also more communality and communal systems of care would be central parts of people's discourse of PSOC. However, the findings show that expectations towards community members to take responsibility for their own PSOC, even though depending on good health, were strong. The expectations that the older adults held toward themselves even in situations of poor health (and in preventing poor health) are to make an effort and be personally involved, mirroring the mentioned individualism of the Norwegian culture. Our findings support other findings of Norwegian older adults' main coping strategy: to accept and adapt [56].

It is likely that by taking responsibility for their own PSOC and well-being by being personally involved and participating in the community, they also shape old age related transitions. For by taking responsibility and making efforts to take part, demanding and difficult transitions in old age become less likely to be undertaken alone. People, as far as they can try as long as possible to be part of community, and as presented, loneliness among Norwegian seniors is not high compared to other countries [35]. However, one may question whether this individual way of handling hardship is actually beneficial for the older individual in cases where individual efforts necessarily come up too short, for example, blaming oneself for being alone after a change in health that reduces physical mobility.

Finally, how people speak about a situation is a vital part of the process behind what makes up society's common sense of how to live [46] [47] [48] [49]. By 
discoursing and prescribing so strongly the responsibility for one's own PSOC and well-being in old age with the transitions entailed, older individuals strongly reproduce the cultural values and expectations of themselves as being responsible for own PSOC and well-being even in old age and having poor health.

To conclude, the overall meaning of PSOC of the Norwegian sample largely reflects the conceptualisation of McMillan and Chavis [10]. Our study also demonstrates how older adults are very active in trying to maintain their PSOC and well-being through life-changing transitions. Finally, our findings further illustrate the importance and value of exploring meanings of PSOC in social contexts where it has not been studied before, as culture, as shown in our study, is clearly reflected in the central premises for PSOC and well-being. Other studies have also shown that PSOC in old age is affected by context [12] [57] [58] [59] [60]. Li, Hodgetts and Sonn [59] study showed results similar to our study; their Chinese older adult New Zealand migrant sample, as our Norwegian city sample, was both active in adapting to transitions and strived to create PSOC within their context. Their argument, however, was that personal social constructions predicated PSOC. As a final point, we will argue that it is important that the interaction between personal and cultural social constructions within one context be explored to build stronger understanding of later-life PSOC.

\section{Practical Implications and Application}

To promote PSOC and well-being among older adults across the world is an important issue in a population-aging world. In Norway the practice of living in the home with the spouse if he or she is alive, or alone as long as possible, is the preferred way of living [33] [61]. Four of five older Norwegian adults in fact live at home and do not receive any support from the local authorities [62]. The majority of older adults in Norway are thus as self-reliant as before within their home and geographic community, which may be a typical situation in many Western countries. The findings of the present Norwegian study suggest that urban older adults have a strong motivation and will to take individual responsibility to participate in their local communities. For society, it is, therefore, important to assist older adults in their initiative and efforts to be responsible and participate in their local communities, including phases of declining health.

Norwegian public eldercare is already offering important assistance through local authorities for integrating older adults with poor health. The city of Oslo, for example, provides economic funding for senior centres (combined with volunteer organisations and foundations) and offers adequate transportation to those who are not able to use their own or public transportation. Given the anticipated increase in the number of older adults in the population, this type of funding and assistance for those with declining health most probably needs to be expanded in the future. Furthermore, it is our hope that Norwegian public eldercare and the city of Oslo may find the empirical findings of this study useful in their efforts to promote, and prevent the decrease of, PSOC among older adult citizens. 
The older adults mentioned the death of spouse, friends or community members as a challenge to PSOC. Family and friends are important to manage the situation of the loss of a spouse in old age [63]. But as shown, senior centrescommunities of peers-are important communities to help older adults who have lost loved ones to feel connected. To secure PSOC and thereby well-being for those older adults who, for whatever reason, are not able to participate in community, and go to senior centres or as some of our informants, do not have children, it may be of great significance that there are offers of someone to come to their home, not only for delivering health services or doing practical jobs, but for spending time with them, talking and listening to them. The new intervention from the Norwegian Directorate of Health to provide "prevention home visits" aiming to give older adults guidance and advice for how to preserve health and the ability to live independently can represent a valuable contribution in this endeavour as this intervention emphasises older adults' efforts and mastery in everyday life and the community. We advise that the application of this intervention allow older adults to choose "preventing conversations" as an initiative (e.g. by volunteers from senior citizens communities or organisations) so that continuous connection to the community can be sustained. In this way, the older adults may still experience being a part of and belonging to the community and society at large in a way that secures their sense of individual responsibility and thereby their self-respect and well-being.

\section{Acknowledgements}

We would like to thank the senior centers and the older adult informants for participating in our study.

\section{References}

[1] Davidson, W.B. and Cotter, P.R. (1991) The Relationship between Sense of Community and Subjective Well-Being: A First Look. Journal of Community Psychology, 19, 246-253.

https://doi.org/10.1002/1520-6629(199107)19:3<246::AID-JCOP2290190308>3.0.C O;2-L

[2] Prezza, M., Amici, M., Roberti, T. and Tedeschi, G. (2001) Sense of Community Referred to the Whole Town: Its Relations with Neighboring, Loneliness, Life Satisfaction, and Area of Residence. Journal of Community Psychology, 29, 29-52. https://doi.org/10.1002/1520-6629(200101)29:1<29::AID-JCOP3>3.0.CO;2-C

[3] Prezza, M. and Costantini, S. (1998) Sense of Community and Life Satisfaction: Investigation in Three Different Territorial Contexts. Journal of Community \& Applied Social psychology, 8, 181-194.

https://doi.org/10.1002/(SICI)1099-1298(199805/06)8:3<181::AID-CASP436>3.0.C $\underline{\mathrm{O} ; 2-4}$

[4] Farrell, S.J., Aubry, T. and Coulombe, D. (2004) Neighborhoods and Neighbors: Do They Contribute to Personal Well-Being? Journal of Community Psychology, 32, 9-25. https://doi.org/10.1002/jcop.10082

[5] Lynch, K.M. (2012) Positive Aging: The Relationships between Satisfaction with Life and Sense of Community with Place of Residence. Ph.D, Publisher, National- 
Louis University, Chicago, IL.

[6] Delle Fave, A., Brdar, I., Wissing, M.P., Araujo, U., Solano, A.C., Freire, T., Hernández-Pozo, M.D.R., Jose, P., Martos, T. and Nafstad, H.E. (2016) Lay Definitions of Happiness across Nations: The Primacy of Inner Harmony and Relational Connectedness. Frontiers in Psychology, 7, 30.

https://doi.org/10.3389/fpsyg.2016.00030

[7] Nelson, G. and Prilleltensky, I. (2005) Community Psychology: In Pursuit of Liberation and Well-Being. Palgrave Macmillan, New York.

[8] Dalton, J.H., Elias, M.J. and Wandersman, A. (2001) Community Psychology. Thomson Wadsworth, Belmont.

[9] Fisher, A.T., Sonn, C.C. and Bishop, B.J. (2002) Psychological Sense of Community: Research, Applications, and Implications. Kluwer Academic, New York. https://doi.org/10.1007/978-1-4615-0719-2

[10] McMillan, D.W. and Chavis, M. (1986) Sense of Community: A Definition and Theory. Journal of Community Psychology, 14, 6-23. https://doi.org/10.1002/1520-6629(198601)14:1<6::aid-jcop2290140103>3.0.co;2-i

[11] Sarason, S.B. (1974) The Psychological Sense of Community: Prospects for a Community Psychology. Jossey-Bass, London.

[12] Zaff, J. and Devlin, A.S. (1998) Sense of Community in Housing for the Elderly. Journal of Community Psychology, 26, 381-398. https://doi.org/10.1002/(SICI)1520-6629(199807)26:4<381::AID-JCOP6>3.0.CO;2$\underline{\mathrm{W}}$

[13] Cheng, S.-T. and Heller, K. (2009) Global Aging: Challenges for Community Psychology. American Journal of Community Psychology, 44, 161-173. https://doi.org/10.1007/s10464-009-9244-x

[14] Provencher, C., Keating, N., Warburton, J. and Roos, V. (2014) Ageing and Community: Introduction to the Special Issue. Journal of Community \& Applied Social Psychology, 24, 1-11. https://doi.org/10.1002/casp.2171

[15] Sonn, C.C., Bishop, B.J. and Drew, N.M. (1999) Sense of Community: Issues and Considerations from a Cross-Cultural Perspective. Community, Work \& Family, 2 , 205-218. https://doi.org/10.1080/13668809908413941

[16] Hill, J.L. (1996) Psychological Sense of Community: Suggestions for Future Research. Journal of Community Psychology, 24, 431-438.

https://doi.org/10.1002/(SICI)1520-6629(199610)24:4<431::AID-JCOP10>3.0.CO;2$\underline{\mathrm{T}}$

[17] Brodsky, A.E. (2009) Multiple Psychological Senses of Community in Afghan Context: Exploring Commitment and Sacrifice in an Underground Resistance Community. American Journal of Community Psychology, 44, 176-187. https://doi.org/10.1007/s10464-009-9274-4

[18] Mannarini, T. and Fedi, A. (2009) Multiple Senses of Community: The Experience and Meaning of Community. Journal of Community Psychology, 37, 211-227. https://doi.org/10.1002/jcop.20289

[19] Talò, C., Mannarini, T. and Rochira, A. (2014) Sense of Community and Community Participation: A Meta-Analytic Review. Social Indicators Research, 117, 1-28. https://doi.org/10.1007/s11205-013-0347-2

[20] Mak, W.W., Cheung, R.Y. and Law, L.S. (2009) Sense of Community in Hong Kong: Relations with Community-Level Characteristics and Residents" Well-Being. American Journal of Community Psychology, 44, 80-92. https://doi.org/10.1007/s10464-009-9242-z 
[21] Malone, M.E. and Dooley, J.P. (2006) Dwelling in Displacement. Community, Work and Family, 9, 11-28. https://doi.org/10.1080/13668800500420947

[22] Bahl, N.K.H. (2011) What is Community to You?: A Critical Discourse Analytical and Indigenous Psychological Exploration of the Contemporary Discourses of Community and Sense of Community among Elderly People in Mumbai. Norwegian University of Science and Technology, Trondheim.

[23] Barbieri, I., Zani, B. and Sonn, C. (2014) Meanings of Community in Contexts of Multiculture: The Role of Citizenship, Identity and Cultural Changes. Journal of Community Psychology, 42, 980-996. https://doi.org/10.1002/jcop.21666

[24] Waid, L.D. and Frazier, L.D. (2003) Cultural Differences in Possible Selves during Later Life. Journal of Aging Studies, 17, 251-268.

[25] Carlquist, E., Nafstad, H.E. and Blakar, R.M. (2007) Community Psychology in a Scandinavian Welfare Society: The Case of Norway. In: Reich, M., Riemer, M., Prilleltensky, I. and Monter, M., Eds., International Community Psychology, Springer, USA, 282-298. https://doi.org/10.1007/978-0-387-49500-2_14

[26] Gullestad, M. (1991) The Transformation of the Norwegian Notion of Everyday Life. American Ethnologist, 18, 480-499. https://doi.org/10.1525/ae.1991.18.3.02a00040

[27] Jonassen, C.T. (1947) The Protestant Ethic and the Spirit of Capitalism in Norway. American Sociological Review, 12, 676-686. https://doi.org/10.2307/2086953

[28] Sandemose, A. (1933) En flyktning krysser sitt spor: Fortelling om en morders barndom. Gyldendal, Oslo.

[29] Silvera, D.H. and Seger, C.R. (2004) Feeling Good about Ourselves. Unrealistic Self-Evaluations and Their Relation to Self-Esteem in the United States and Norway. Journal of Cross-Cultural Psychology, 35, 571-585. https://doi.org/10.1177/0022022104268389

[30] Triandis, H.C. and Gelfand, M.J. (1998) Converging Measurement of Horizontal and Vertical Individualism and Collectivism. Journal of Personality and Social Psychology, 74, 118-128. https://doi.org/10.1037/0022-3514.74.1.118

[31] Triandis, H.C. (2001) Individualism and Collectivism: Past, Present, and Future. In: Matsumoto, D., Ed., The Handbook of Culture and Psychology, Oxford University Press, Oxford, 35-50.

[32] Nafstad, H.E., Blakar, R.M., Carlquist, E., Phelps, J.M. and Rand-Hendriksen, K. (2007) Ideology and Power: The Influence of Current Neo-Liberalism in Society. Journal of Community \& Applied Social Psychology, 17, 313-327. https://doi.org/10.1002/casp.931

[33] Daatland, S.O. and Solem, P.E. (2011) Aldring og samfunn: Innføring i sosialgerontologi. Fagbokforlaget, Bergen.

[34] Daatland, S.O. and Herlofson, K. (2004) Families, Welfare States, and Ageing. Intergenerational Solidarity in a European Perspective. NOVA Report 7/04.

[35] Hansen, T. and Slagsvold, B. (2015) Late-Life Loneliness in 11 European Countries: Results from the Generations and Gender Survey. Social Indicators Research, 129, 445-464. https://doi.org/10.1007/s11205-015-1111-6

[36] Engebrigtsen, A. and Danielsen, K. (2010) Bor det noen gamle her' a? Eldreliv i fire kommuner. Norwegian Social Research.

[37] Grøtvedt, L. (2002) Helseprofil for Oslo [Health Profile for Oslo]. National institute for Public Health, Oslo Municipality, Program for Research in Main Cities, Oslo.

[38] Muncipality of Oslo (2011) Oslotrender 2011: Vedlegg til høringsutkast til planstra- 
tegi og planprogram for Kommuneplan 2013 (Byrådsavdeling for finans og næring; Oslo: Muncipality of Oslo).

[39] Ingebretsen, R. (2010) Experiences from Care Services for Elderly Immigrants. NOVA Report, 15/10.

[40] Bishop, B., Colquhoun, S. and Johnson, G. (2006) Psychological Sense of Community: An Australian Aboriginal Experience. Journal of Community Psychology, 34, 1-7. https://doi.org/10.1002/jcop.20079

[41] Fyson, S.J. (2008) Using Discourse Analysis and Psychological Sense of Community to Understand School Transitions. Journal of Community Psychology, 36, 452-467. https://doi.org/10.1002/jcop.20247

[42] Carlson, N., Martin, G. and Buskist, W. (2007) Psychology. Pearson Education Limited, Harlow, Pearson Education, Harlow, Essex.

[43] Weiss, R.S. (1994) Learning from Strangers: The Art and Method of Qualitative Interview Studies. The Free Press, New York.

[44] Clarke, V., Braun, V. and Hayfield, N. (2015) Thematic Analysis. In: Smith, J.A., Ed., Qualitative Psychology. A Practical Guide to Research Methods, SAGE Publications, London, 222-248.

[45] Braun, V. and Clarke, V. (2006) Using Thematic Analysis in Psychology. Qualitative Research in Psychology, 3, 77-101. https://doi.org/10.1191/1478088706qp063oa

[46] Billig, M. (2001) Discursive, Rhetorical and Ideological Messages. In: MagarettWetherell, S.T. and Yates, S.J., Eds., Discourse Theory and Practice: A Reader, Sage Publications, New Delhi, 210-221.

[47] Gee, J.P. (2014) An Introduction to Discourse Analysis: Theory and Method. Routledge, Oxon.

[48] Fairclough, N. (2010) Critical Discourse Analysis: The Critical Study of Language. Prentice Hall, Upper Saddle River. https://doi.org/10.4324/9780203809068.ch1

[49] Nafstad, H.E. and Blakar, R.M. (2012) Ideology and Social Psychology. Social and Personality Psychology Compass, 6, 282-294. https://doi.org/10.1111/j.1751-9004.2012.00428.x

[50] Wodak, R. and Meyer, M. (2009) Methods for Critical Discourse Analysis. Sage Publications, New Delhi.

[51] Gee, J.P. (2014) How to Do Discourse Analysis. 2nd Edition: A Toolkit. Routledge, Oxon.

[52] Delacroix, J. and Nielsen, F. (2001) The Beloved Myth: Protestantism and the Rise of Industrial Capitalism in Nineteenth-Century Europe. Social Forces, 80, 509-553. https://doi.org/10.1353/sof.2001.0096

[53] Nowell, B. and Boyd, N. (2010) Viewing Community as Responsibility as Well as Resource: Deconstructing the Theoretical Roots of Psychological Sense of Community. Journal of Community Psychology, 38, 828-841.

https://doi.org/10.1002/jcop.20398

[54] McMillan, D.W. (2011) Sense of Community, a Theory Not a Value: A Response to Nowell and Boyd. Journal of Community Psychology, 39, 507-519. https://doi.org/10.1002/jcop.20439

[55] Nowell, B. and Boyd, N. (2011) Sense of Community as Construct and Theory: Authors” Response to McMillan. Journal of Community Psychology, 39, 889-893. https://doi.org/10.1002/jcop.20504

[56] Birkeland, A. and Natvig, G.K. (2009) Coping with Ageing and Failing Health: A Qualitative Study among Elderly Living Alone. International Journal of Nursing 
Practice, 15, 257-264. https://doi.org/10.1111/j.1440-172X.2009.01754.x

[57] Brossoie, N. (2003) Community Connections and Sense of Community among Older Adults. Virginia Polytechnic Institute and State University.

[58] Toohey, A.M., McCormack, G.R., Doyle-Baker, P.K., Adams, C.L. and Rock, M.J. (2013) Dog-Walking and Sense of Community in Neighborhoods: Implications for Promoting Regular Physical Activity in Adults 50 Years and Older. Health \& Place, 22, 75-81.

[59] Li, W.W., Hodgetts, D. and Sonn, C. (2014) Multiple Senses of Community among Older Chinese Migrants to New Zealand. Journal of Community \& Applied Social Psychology, 24, 26-36. https://doi.org/10.1002/casp.2174

[60] Busson, D.M. (2012) Residents' Perceptions of Quality of Life in a Culturally Diverse Long-Term Care Environment. Doctoral Dissertation, The University of Akron, Akron.

[61] Daatland, S.O. (2014) Changes in Long-Term Care in Norway. NOVA Report $16 / 14$.

[62] Ramm, J. (2013) Eldres bruk av Helse- og omsorgstjenester. Statistisk sentralbyrå, Oslo.

[63] Gjertsen, H. (2004) Tap av ektefelle i eldre år: Sorg og mestring. En sosiologisk analyse. University of Tromsø, Tromsø.

Scientific Research Publishing

Submit or recommend next manuscript to SCIRP and we will provide best service for you:

Accepting pre-submission inquiries through Email, Facebook, LinkedIn, Twitter, etc. A wide selection of journals (inclusive of 9 subjects, more than 200 journals)

Providing 24-hour high-quality service

User-friendly online submission system

Fair and swift peer-review system

Efficient typesetting and proofreading procedure

Display of the result of downloads and visits, as well as the number of cited articles

Maximum dissemination of your research work

Submit your manuscript at: http://papersubmission.scirp.org/

Or contact jss@scirp.org 